\title{
Validation of Optimized Method for Quantitative Estimation of Extracellular Ethanol from Micro-algae
}

\section{Nishant Saxena ${ }^{1}$, Preeti Singh ${ }^{1}$, Debanjan Sanyal ${ }^{1 *}$ and Santanu Dasgupta $^{2}$}

${ }^{1}$ Research and Development, Reliance Industries Ltd, Jamnagar, India

${ }^{2}$ Research and Development, Reliance Corporate Park, Ghansoli, Navi-Mumbai,

India

*Corresponding Author: Debanjan Sanyal, Research and Development, Reliance

Industries Ltd, Jamnagar, India.
Received: April 01, 2021

Published: May 17,2021

(C) All rights are reserved by Debanjan

Sanyal., et al.

\section{Abstract}

Identification and quantification of ethanol in biological samples such as algae, is of paramount importance for research and quality laboratories. An accurate quantification with minimum standard deviation is still a challenging task due to high interference of salts, ions, metals and biological contaminations. A rapid method for the determination of ethanol content in algae samples was validated for seven parameters using gas chromatography. The study was conducted here, to confirm it's specificity, linearity, accuracy, precision, robustness, sensitivity, and suitability for ethanol estimation in micro-algae samples. During specificity analysis, retention time of ethanol were found 3.27 minutes for standard and 3.25 minutes for sample, which were statistically similar. The linearity of this method for ethanol estimation was found till 5000 ppm for both standard and sample and $\mathrm{R}^{2}$ were 1 and 0.9953 respectively. In the recovery study, the $100 \%$ ethanol were recovered from standard and sample with a standard deviation of less than $2 \%$. Repeatability study demonstrated that, the method was found more precise and observed $<1 \%$ standard deviation for peak retention time and peak area, similarly $<2 \%$ standard deviation was observed among the 10 replicates of standard. In the ruggedness analysis, significant differences were not observed on ethanol content by different analysts on different days of analysis. In the robustness analysis the variation of flow rate, oven temperature and column did not affect the final results of ethanol content significantly. It was found from sensitivity analysis that, this analytical method can detect $>1.36 \mathrm{ppm}$ and can accurately quantify $>4.13$ ppm ethanol of algae sample. Validated data indicated that, GC-FID-HSS method is more specific, linear, accurate, repeatable, rugged, robust and sensitive for ethanol estimation. Hence this method can be used effectively to estimate ethanol content in algae samples without any interference from ions, salts, metals and biological contamination.

Keywords: Accuracy; Algae Sample; DB Wax; Ethanol Content; GC-FID-HS

\section{Introduction}

Sustainable energy could be a big challenge for the growing population of the earth. The world's population will still grow for a minimum of several decades. Demand for energy will prob- ably increase even faster, for satisfying the fuel requirement of this huge population. Available resources of fuel are exhausting gradually, which has ultimately increased the value of petroleum fuels [1]. Moreover, many environmental issues like increment in global 
temperature and sea level has emerged with the incredible use of reserved fuel. Excited energy demands and global temperature change, have brought interest on alternate energy source such as bio-fuels. Environmental-friendly energy sources were considered as good option to satisfy current and future energy needs by the scientists. These are substituting, inexhaustible and capable for low-emitting greenhouse gases [2]. Liquid fuels like bio-ethanol, bio-diesel, bio-gas such as methane and solids like charcoal can be produced mainly from biomass are worldwide termed as biofuel $[3,4]$. Bio-fuels derived from biomass has the capability to renew petroleum fuels and bring environmental benefits as well $[5,6]$. Many developed and developing countries are working towards bio-fuels which is important for various aspects such as scale back dependence on oil, reducing greenhouse gases emission and achieving rural development goals [7]. Many conventional bio-fuels are overloaded with higher production costs and thus, scientists are working on the sustainability of the bio-fuel/bio-ethanol productions worldwide [8]. However, political support through mergers and relaxation in policies has allowed some types to penetrate the marketplace for consumer fuels, with sugar ethanol in Brazil being an outstanding example [9]. It is always necessary to seek out renewable raw materials with suitable compositions concerning hydrocarbons.

In accordance with the feed stocks are considered, there are three generations of bio-ethanol. The first generation, where bioethanol is produced from human food ingredients (e.g., soybean, wheat, rice, corn, sugarcane, etc.). Second generation bio-ethanol from lingo-cellulosic materials/agro-industrial residues (e.g. straw of wheat, bagasse of sugar cane and agave etc.). Third generation bio-ethanol produced from aquatic biomass (such as macroalgae, and micro-algae) [10]. Among these, aquatic biomass especially micro algae biomass has been highlighted in recent years due to its high lipid content and higher growth rate, it also has higher potential for bio-fuel and bio-ethanol production [11]. Micro-algae have the capability to produce high amount of lipid, protein and carbohydrate in a short time by photosynthesis. They can survive in various environmental conditions as they are equipped with unicellular or simple cell structures [12].

Bio-ethanol are often produced through different bio-refinery based processes [13]. Besides biodiesel and bio-ethanol there are many high value products and sub-products produced as well from micro algae such as bio gas [14], bio-butanol, acetone [15], omega 3 oil and fatty acid [16], livestock feed [17], pharmaceuticals and cosmetics products [18]. Especially sub-products are preferred for economic support of main process [19]. A number of the micro-algae such as blue-green alga has the potential to supply bio-ethanol directly as an extracellular compound without fermentation. Bioethanol is readily biodegradable, rich in oxygen, and emits lesser airborne pollutants as compared to petroleum fuel. Therefore, is taken into account to be the most effective oxygenate within the world [20]. The additional oxygen helps to balance petrol to burn more efficiently within the vehicle engine, thereby reducing vehicular emissions and decreases environmental pollution. Indirectly bio-ethanol accordingly helps in improving air quality, so ethanol blending with gasoline has been initiated everywhere around the globe to protect environment. Due to this blending ethanol demand is increasing globally [21].

Accurate and precise analytical technique for ethanol estimation in micro-algae sample is imperative. Ethanol is the commonest analyte and various analytical methods are available for its identification and quantification such as calorimetric technique, high pressure liquid chromatography (HPLC) and gas chromatography (GC) using flame ionization detector (FID) [22]. Major challenges to identify ethanol from micro-algae samples are interference of salts, ions, metals and biological contaminations.

In this study, GC-FID method with head space sampler (HSS) was evaluated to overcome above mentioned challenges. Few methods for ethanol analysis by GC-FID-HSS are published. However, no literature is available on ethanol estimation by GC-FID-HSS for micro-algae samples. The validation of GC-FID-HSS analytical method was conducted here, to confirm its specificity, linearity, accuracy, precision, robustness, sensitivity, and suitability for ethanol estimation in micro-algae samples.

\section{Materials and Methods}

Material

- Ethanol internal standard (Make-Cole Parmer) of 99.9\% purity.

- Milli-Q water was obtained from a Millipore Direct-Q ultrapure water system.

- Biological samples of Cyanobacterium sp. 


\section{Culture conditions and medium}

The micro-algae Cyanobacterium sp. used for this study, was obtained from Reliance Industries Ltd. germplasm repository and maintained on agar slants. Same culture was developed $5 \mathrm{~L}$ using urea phosphoric acid (UPA) medium under controlled conditions with temperature of $26 \pm 2{ }^{\circ} \mathrm{C}$, $\mathrm{pH} 7.0-7.5,3.5 \%$ salinity, $2 \% \mathrm{CO}_{2}$ and $250 \mu \mathrm{mol} \mathrm{m} \mathrm{m}^{-2} \mathrm{~s}^{-1}$ of light intensity at 12:12 light/dark cycle for validation purpose. This culture was grown till 5 optical density (OD) and whole culture was used for analysis of all validation parameters after spiking ethanol at different levels and concentrations.

Analytical method for ethanol estimation by gas chromatography

A gas chromatographic system (GC- 7890 B of Agilent Technologies, Santa Clara, California, USA) equipped with a flame ionization detector and an automated head space liquid sampler (HSS-7697A) was used for method validation. DB-WAX 123-7062 capillary column of $60 \mathrm{~m}$ length, $0.32 \mathrm{~mm}$ internal diameter and $0.25 \mu \mathrm{m}$ film thickness was used.

\section{Method conditions}

All samples were analyzed by GC instrument with a head space by maintaining oven temperature of $80^{\circ} \mathrm{C}$. The HSS loop and transfer line temperatures were set at $85^{\circ} \mathrm{C}$ and $100^{\circ} \mathrm{C}$ respectively. Vial equilibrating was fixed for 15 minutes. The HSS vial pressurization was fixed at 15 psi for 0.15 minutes. Injection, loop fill and loop equilibrating times were set at $0.50,0.15$ and 0.05 minutes, correspondingly. Multi HSS extraction and vial shaking was set to off. The GC cycle time was set at 25 minutes (Table 1). A constant nitrogen gas flow rate of $3 \mathrm{ml} /$ minute was retained by GC during entire cycle. The temperature of injector port was maintained at $250^{\circ} \mathrm{C}$, a septum purge flow of $3 \mathrm{ml} /$ minute was fixed and split ratio was 1:25 of injection volume. The initial GC oven temperature of $50^{\circ} \mathrm{C}$ was hold for 10 minute. Ramping is not required since method has designed for estimation of only single hydrocarbon (ethanol). The GC run time was 10 minutes/sample and GC cycle time was 25 minutes/sample. The FID temperature was maintained at $250^{\circ} \mathrm{C}$ with hydrogen, air, and nitrogen makeup pressures of 40,450, and 50 psi, respectively. The FID signal was zeroed at 0 minute with a data collection rate of $10 \mathrm{~Hz}$ (Table 2).

\begin{tabular}{|l|c|}
\hline Vial/Oven Temperature & $80^{\circ} \mathrm{C}$ \\
\hline Loop Temperature & $85^{\circ} \mathrm{C}$ \\
\hline Transfer line temperature & $100^{\circ} \mathrm{C}$ \\
\hline GC cycle Time & 25 minutes \\
\hline Injection Duration & 1 minute \\
\hline Vial equilibration Time & 15 minutes \\
\hline Injection Volume & 1 ml \\
\hline
\end{tabular}

Table 1: Conditions of head space sampler.

\begin{tabular}{|l|c|}
\hline Injector Temperature & $250^{\circ} \mathrm{C}$ \\
\hline Detector Temperature & $250^{\circ} \mathrm{C}$ \\
\hline Oven Temperature & $50^{\circ} \mathrm{C}$ \\
\hline Hold Time & 10 minutes \\
\hline Split ratio & $1: 25 \mathrm{Split}$ ratio \\
\hline Flow rate of carrier gas (Nitrogen) & $3.0 \mathrm{ml} /$ minute \\
\hline Hydrogen gas flow rate & $30 \mathrm{ml} /$ minute \\
\hline Instrument air flow rate & $300 \mathrm{ml} /$ minute \\
\hline GC Run Time & $10 \mathrm{minutes}$ \\
\hline
\end{tabular}

Table 2: Conditions of gas chromatograph.

Standard and sample solutions

Ethanol stock solutions A and B of 5000 ppm were prepared by dissolving $5000 \mathrm{mg}$ of $99.9 \%$ ethanol in Milli-Q water and lab grown algae cultures respectively. The sub stock prepared in Milli$\mathrm{Q}$ water was considered as standard and the sub stock prepared in algal sample was named as sample solution. Sub stocks of various concentrations were prepared from the above stocks for validation study and Milli-Q water used as a blank.

\section{Validation of analytical method for ethanol estimation}

Analytical method validation is the process of proving and documenting that specific method, provides precise and accurate analytical data which is acceptable for the intended use. The analytical method of ethanol estimation by HSS-GC-FID was validated by evaluating specificity, accuracy/recovery, precision (repeatability, ruggedness and robustness), linearity, and sensitivity as per the international council for harmonization (ICH) method validation guidelines (Figure 1) [23]. 


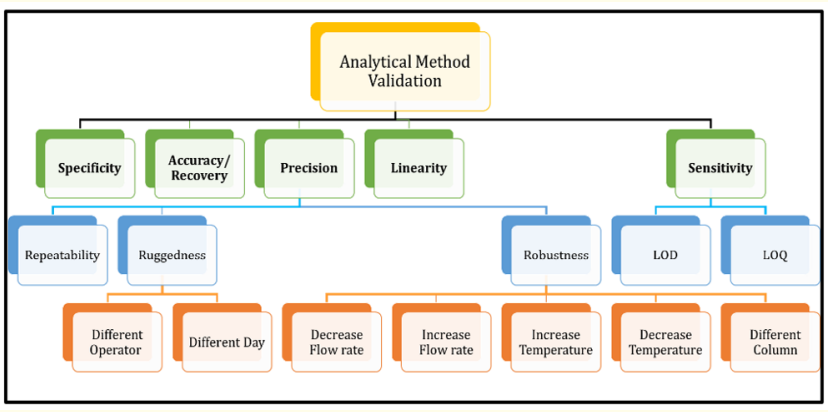

Figure 1: Process flow diagram for analytical method validation.

Specificity

Ethanol standard and sample solution of $100 \mathrm{ppm}$ was prepared by diluting stock solution A and B in Milli-Q water and algae sample respectively. 5 blanks, 3 standard solutions and 3 algae samples were injected separately into GC and followed above mentioned conditions of GC and HSS. Retention time (RT) of ethanol peak in standard and sample was measured. The mean and percent relative standard deviation (RSD) of RT were calculated separately for standard as well as sample. Acceptance criteria for RSD of RT was considered maximum $1.0 \%$ as per ICH guideline.

\section{Linearity}

It is calculated in accordance to established mathematical relationship among peak area obtained by the analysis of ethanol at varying concentrations. Ethanol standard and sample solutions of six different concentrations such as 100, 500, 1000, 2000, 3000 and $5000 \mathrm{ppm}$ were prepared in water and algae sample respectively. All solutions were analyzed using the same chromatographic conditions as shown above and recorded peak area. Linearity curve was plotted between theoretical ethanol concentration and peak area, slope and correlation coefficient was also calculated. These slope values were further used for quantification of ethanol in water and algae samples respectively. Acceptance criteria for correlation coefficient of the regression line $\left(R^{2}\right.$ value) was considered minimum 0.98 .

\section{Accuracy}

The recovery experiment was carried out to evaluate the accuracy of this method. Three different treatments of algae samples were prepared by spiking $0.5 \mathrm{ml}, 1.0 \mathrm{ml}$ and $2.0 \mathrm{ml}$ volume of 100 ppm ethanol standard with respect to target related compound concentration. 3 vials of $10 \mathrm{ml}$ were taken for each concentration, $5 \mathrm{ml}$ respective sample was poured in each vial and all vials (3 for each concentration) were placed into the HSS system followed by blank. The recoveries were calculated from the response of each ethanol peak on FID detection. Mean ethanol content concentration was calculated using mean area for each treatment. Percent recovery of ethanol was calculated at all three levels by comparing the measured ethanol concentration with theoretical ethanol concentration and acceptance criteria for\% recovery was considered $100 \pm 5 \%$ as per ICH guideline.

\section{Precision}

Prepared algae sample of 2000, 2400 and $2700 \mathrm{ppm}$ ethanol by adding 2000, 2400 and 2700 mg ethanol standard in 1 liter algae samples separately. These samples were used during various studies of precision as explained below.

\section{Repeatability}

Sample of $2000 \mathrm{ppm}$ was injected ten times from different vials and recorded ethanol RT, area, height and concentration. RSD for ethanol RT, peak area, peak height and ethanol content were calculated and acceptance criteria were considered maximum $1 \%, 2 \%$, $2 \%$ and $2 \%$ respectively as per ICH guideline.

\section{Ruggedness}

Previously prepared sample of 2400 ppm was used for ruggedness analysis. This study was performed in two stages to examine ruggedness of this analytical method. During the first stage same sample was analyzed in triplicate at two different days while, during second stage same sample was analyzed in triplicate by two different analysts. Chromatographic conditions were followed same as mentioned above. Injected sample of $2400 \mathrm{ppm}$ three times for each study and calculated RSD for ethanol concentration. Acceptance criteria of RSD for ethanol concentration was considered $2 \%$ and difference in ethanol content should not be more than $5 \%$ as per ICH guideline.

\section{Robustness}

This study was executed in three phases by deviating three GC conditions (Flow rate, oven temperature and GC column) of this analytical method using ethanol sample of $2700 \mathrm{ppm}$. During first 
phase, standard flow rate of $3 \mathrm{ml} /$ minute was deviated $\pm 0.5 \mathrm{ml} /$ minute ( 3.0 to $3.5 \mathrm{ml} / \mathrm{minute}$ and 3.0 to $2.5 \mathrm{ml} /$ minute). In second phase, standard oven temperature of $50^{\circ} \mathrm{C}$ was deviated $\pm 10^{\circ} \mathrm{C}$ $\left(50^{\circ} \mathrm{C}\right.$ to $60^{\circ} \mathrm{C}$ and $50^{\circ} \mathrm{C}$ to $\left.40^{\circ} \mathrm{C}\right)$. Standard GC column (DB-WAX) was replaced with another GC column (DB 624) in third phase of study. All samples were injected in triplicates during all phases of study. RSD was calculated for ethanol peak RT, area and ethanol content, acceptance criteria for RSD was considered maximum 1\%, $2 \%$ and $5 \%$ correspondingly. According to the principle of GC-FID, ethanol content should not differ more than $5 \%$ by deviating these conditions.

\section{Sensitivity}

This analysis is known to estimate the proportion of actual analyte with specific compound (ICH Guideline 1996). Ethanol standard stock solution of 100 ppm was prepared by adding $100 \mathrm{mg}$ of ethanol in $1000 \mathrm{ml}$ of water. Six different concentrations such as $0.2,0.5,1.0,2.0,3.0$ and $5.0 \mathrm{ppm}$ were prepared from $100 \mathrm{ppm}$ stock solution in algae sample. Sensitivity was measured by analyzing limit of detection and quantification.

\section{Limit of detection}

In analytical science limit of detection (LOD), is the lowest quantity of any substance which can be detected with a stated confidence level.

\section{Limit of quantification}

Limit of quantification (LOQ) is the lowest analyst concentration that can be quantified with a stated accuracy and precision. The calibration curve was plotted first and slope value was calculated. Same slope was used for calculating LOD and LOQ with the help of standard error (SE) and standard deviation (SD) of intercept. These SE and SD values were calculated from regression statics with the help of Microsoft excel.

\section{Results and Discussion Specificity}

According to the recorded GC chromatogram of blank straight line was found and no interfering peaks were detected near to the RT of ethanol. The RT of ethanol in sample was confirmed by comparing it with RT of ethanol internal standard. Mean RT of ethanol standard and sample was observed 3.27 and 3.25 minutes followed by RSD of $0.04 \%$ and $0.02 \%$ respectively (Figure 2 ). Observed RSDs were with-in the acceptance criteria of $1.0 \%$; hence this method complies in specificity test of validation. As per the available literatures, scientists have analyzed ethanol in various types of samples however, no information was available to estimate ethanol in microalgae sample. Helena., et al. determined various volatile solvents including ethanol in cell culture medium samples using GC. RT of ethanol was reported $3.16 \pm 0.1$ minutes during specificity analysis of validation [24]. Peak RT for specific compound should not deviate, if GC condition and column are same, since RT of any compound depends on GC conditions and column specification.

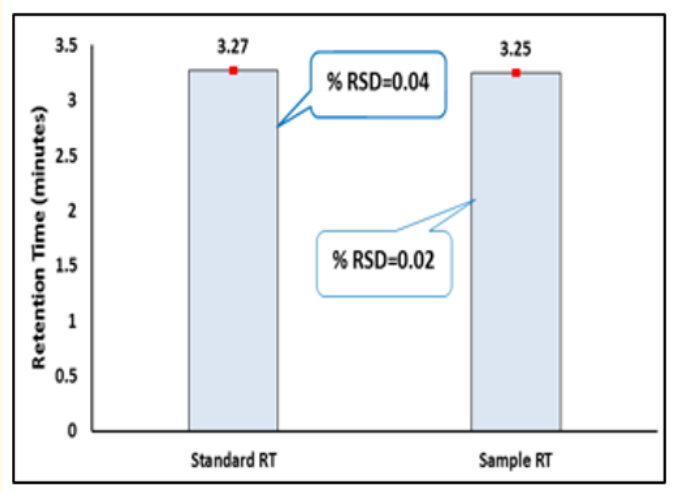

Figure 2: Mean retention time of ethanol peak.

\section{Linearity}

Ethanol standard and micro-algae sample have reflected correlation coefficient of the regression line ( $\mathrm{R}^{2}$ value) 1.000 and 0.9953 respectively, which is statistically satisfactory and meets the acceptance criteria (> 0.98) of the ICH guideline as well (Figure 3 and 4). This method has showed linearity till $5000 \mathrm{ppm}$ from $100 \mathrm{ppm}$ since, this range meets analytical requirement to estimate ethanol in all algae samples. According to the observed data and plotted linearity curve this analytical method is stable to analyze ethanol content till 5000 ppm in both media namely, standard as well as micro-algae samples. No literature was found for linearity analysis of ethanol in microalgae samples, however, for cell culture medium sample correlation coefficients $\left(\mathrm{R}^{2}\right)$ were observed $>0.99$, from 75 to $2400 \mathrm{ppm}$ for various organic solvents including ethanol [24]. Tiscione., et al. generated linear curves for the aqueous, urine, and whole blood standards by 4 different analysts including ethanol for 
18 different days, during analytical method validation. The method has shown to be linear with a coefficient of determination $\left(\mathrm{R}^{2}\right)$ of 1.000 for all matrices [22].

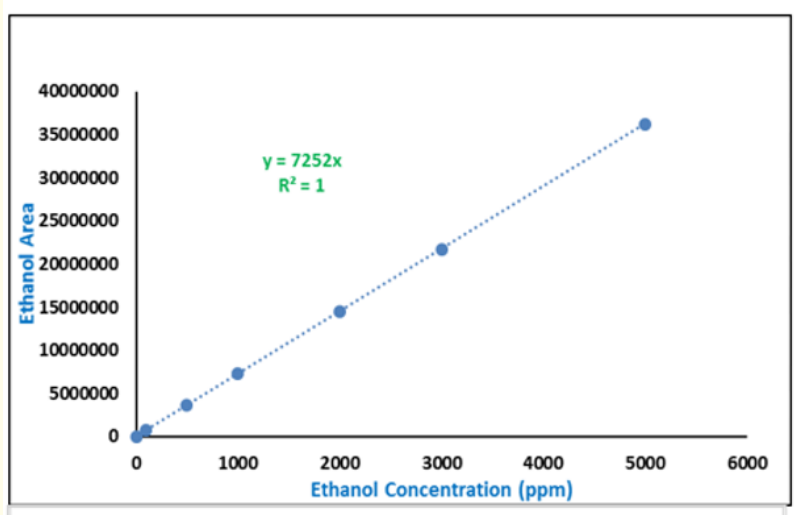

Figure 3: Linearity curve- ethanol standard.

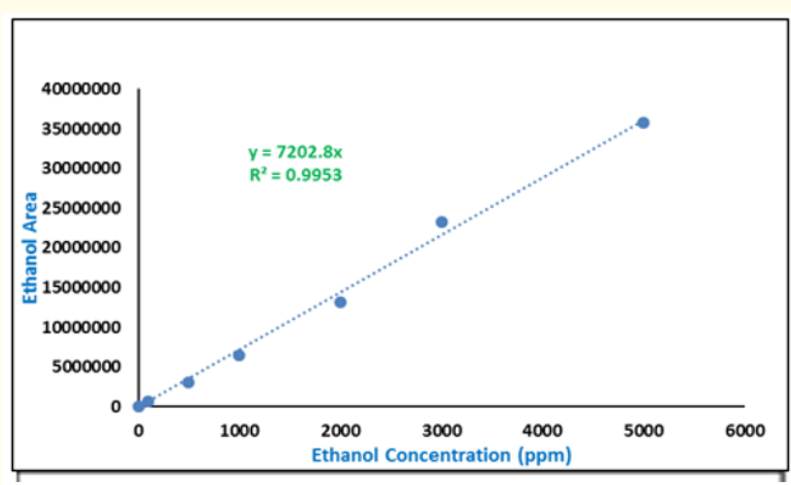

Figure 4: Linearity curve- ethanol sample.

\section{Accuracy}

Recoveries of three levels, $0.5,1.0$ and $2.0 \mathrm{ml}$ of spiked ethanol samples in triplicate yielded $98.0 \%, 99.9 \%$ and $96.4 \%$ respectively and mean recovery was observed $98.1 \%$. The results of accuracy have demonstrated that, this analytical method of ethanol estimation meet acceptance criteria $(100 \% \pm 5)$ and is capable for the accurate quantification of ethanol in algal samples (Table 3). Ethanol recovery in red wine and whiskey samples were reported by Wang., et al. after spiking 50 and $100 \mathrm{mg}$ of ethanol. However, no published literatures are available so far for ethanol recovery in algae samples [25].

\begin{tabular}{|l|c|c|c|}
\hline $\begin{array}{c}\text { S. } \\
\text { No. }\end{array}$ & $\begin{array}{c}\text { Mean } \\
\text { Concentration } \\
\text { (Theoretical) }\end{array}$ & $\begin{array}{c}\text { Mean } \\
\text { Concentration } \\
\text { (Observed) }\end{array}$ & \% Recovery \\
\hline 1 & 1330 & 1304 & 98.0 \\
\hline 2 & 1541 & 1539 & 99.9 \\
\hline 3 & 1686 & 1623 & 96.4 \\
\hline
\end{tabular}

Table 3: Summarized results of accuracy.

\section{Precision}

Repeatability

The repeatability was evaluated using the analytical results of 10 preparations of ethanol in algae sample. Mean of 10 preparations were 3.25 for peak RT, 13973178 for peak area, 7237452 for peak height and 1940 ppm of ethanol. The RSDs of ethanol peak, area, height and content were observed 0.02\%, 0.93\%, 1.19\% and $0.93 \%$ respectively (Table 4 ). All values of RSDs were within the acceptance criteria, which was considered maximum 1\%, 2\% and 2\% respectively for mean RT, area and height. (Tiscione., et al. 2011) also validated GC analytical method for ethanol estimation in blood sample, and none has done validation for ethanol estimation in microalgae samples before. During precision analysis by Tiscione., et al. 40 replications of ethanol were used, where percent RSD of ethanol content was $0.64 \%$ for intraday precision in blood sample [22]. Ethanol content was calculated using peak area and it is directly proportional to each other.

\section{Ruggedness}

The ruggedness of this analytical method was evaluated on the basis of the data generated on different days and by different analysts using microalgae samples. The difference of the mean ethanol concentration from two day's analysis was observed as $1.13 \%$ and from two analysts was observed as $3.47 \%$. The RSDs for ethanol content were $0.41 \%, 1.27 \%, 0.82 \%$ and $0.96 \%$ for analysis performed at day-1, day-2, analyst-1 and analyst-2 respectively. Mean concentration of ethanol was observed statistically similar which proves that there is no impact of different days and analysts on ethanol concentration (Figure 5). This study was not done in microalgae samples earlier, while Argasiska., et al. calculated intermediate 


\begin{tabular}{|l|c|c|c|c|}
\hline Replications & $\begin{array}{c}\text { Retention } \\
\text { Time } \\
\text { (minutes) }\end{array}$ & Peak Area & $\begin{array}{c}\text { Peak } \\
\text { Height }\end{array}$ & $\begin{array}{c}\text { Ethanol } \\
\text { Content } \\
\text { (ppm) }\end{array}$ \\
\hline 1 & 3.251 & 13711303 & 7100909 & 1904 \\
\hline 2 & 3.253 & 13798387 & 7217130 & 1916 \\
\hline 3 & 3.252 & 13978160 & 7220597 & 1941 \\
\hline 4 & 3.252 & 14114746 & 7307771 & 1960 \\
\hline 5 & 3.251 & 14101422 & 7348425 & 1958 \\
\hline 6 & 3.252 & 14026998 & 7191220 & 1948 \\
\hline 7 & 3.251 & 14069690 & 7295844 & 1954 \\
\hline 8 & 3.251 & 13966234 & 7168328 & 1939 \\
\hline 9 & 3.252 & 13930810 & 7165952 & 1934 \\
\hline 10 & 3.253 & 14034026 & 7358353 & 1949 \\
\hline Mean & 3.25 & 13973178 & 7237452 & 1940 \\
\hline SD & 0.00079 & 130554 & 86058 & 18.13 \\
\hline$\%$ RSD & 0.02 & 0.93 & 1.19 & 0.93 \\
\hline
\end{tabular}

Table 4: Results of repeatability.

precision for ethanol content by GC at different days using ointment samples [26]. The observed percent RSD for ethanol content was $1.53 \%$, which was also within the acceptance criteria of $2.0 \%$ and indicating that analytical method complies in ruggedness.

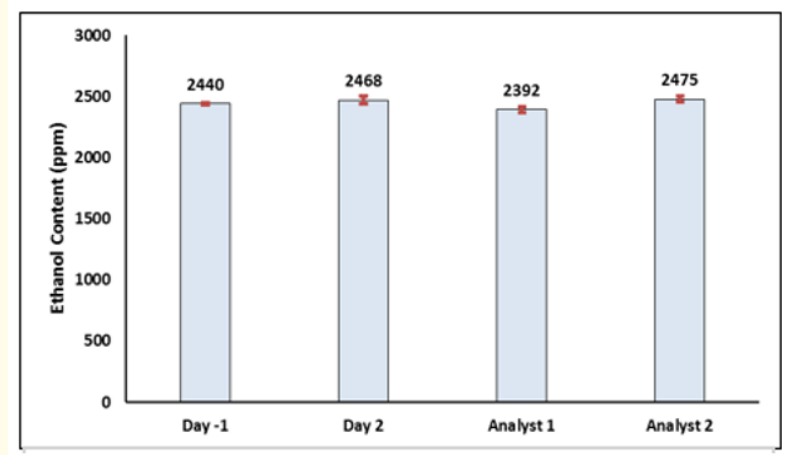

Figure 5: Ethanol content for ruggedness analysis.

Robustness at multiple flow rates

During this study, difference in ethanol content was observed $4.4 \%$ and $2.9 \%$ at flow rate of $2.5 \mathrm{ml} /$ minute and $3.5 \mathrm{ml} /$ minute respectively, as compared to ethanol content at standard flow rate of $3 \mathrm{ml} /$ minute. Reported RSD was $0.02 \%$ for ethanol peak RT at all flow rates. RSDs were observed $0.17 \%, 0.82 \%$ and $0.53 \%$ for ethanol area, $0.17 \%, 0.85 \%$ and $0.53 \%$ for ethanol content at flow rate of $2.5,3.0$ and $3.5 \mathrm{ml} /$ minute respectively. All these values are meeting the acceptance criteria of $1 \%, 2 \%$ and $5 \%$ for RT, area and ethanol content (Table 5). Mean ethanol content was observed statistically similar even under various flow rate conditions, indicating that there is no difference in ethanol estimation by varying flow rate $\pm 5 \mathrm{ml} /$ minute from the standard flow rate of $3.0 \mathrm{ml} /$ minute.

\begin{tabular}{|l|c|c|c|}
\hline S. No. & $\begin{array}{c}\text { At } \mathbf{2 . 5} \mathbf{~ m l} / \\
\text { minute }\end{array}$ & $\begin{array}{c}\text { At } \mathbf{3 . 0} \mathbf{~ m l} \\
\text { minute }\end{array}$ & $\begin{array}{c}\text { At } 3.5 \mathrm{ml} / \\
\text { minute }\end{array}$ \\
\hline 1 & 2579 & 2683 & 2608 \\
\hline 2 & 2582 & 2692 & 2635 \\
\hline 3 & 2588 & 2727 & 2626 \\
\hline Mean & 2583 & 2701 & 2623 \\
\hline \% RSD & 0.17 & 0.85 & 0.53 \\
\hline
\end{tabular}

Table 5: Ethanol content at multiple flowrates.

\section{Robustness at various oven temperatures}

During this study difference in ethanol content was observed $4.7 \%$ at $40{ }^{\circ} \mathrm{C}$ and $60{ }^{\circ} \mathrm{C}$ oven temperature, as compared to ethanol content at standard oven temperature of $50^{\circ} \mathrm{C}$. Ethanol peak RT has showed $0.02 \%$ RSD at all different oven temperatures. According to the robustness data, RSD for ethanol area and ethanol content was also reported same as $0.14 \%$ and $0.10 \%$ at $40^{\circ} \mathrm{C}$ and $60^{\circ} \mathrm{C}$ respectively. All these values of RSDs were meeting the acceptance criteria of 1\%, $2 \%$ and $5 \%$ for RT, area and ethanol content at all temperatures (Table 6). Mean ethanol content was observed statistically similar at different oven temperatures. This data demonstrates that if oven temperature deviated $\pm 10^{\circ} \mathrm{C}$ from standard temperature of $50^{\circ} \mathrm{C}$, it impacts only on peak RT and area, however, no difference was observed in ethanol concentration. According to the Batista., et al. acceptance criteria of robustness were considered maximum 5.0\% for ethanol content [27]. Syrup sample was used for robustness analysis, however, this study was not done in algae samples earlier. Maximum difference in ethanol content was observed $3.1 \%$ after reducing oven temperature by $2{ }^{\circ} \mathrm{C}$.

\section{Robustness using different GC columns}

During this study, difference in ethanol content was observed only 1 ppm between the two GC columns used. RSDs for ethanol 


\begin{tabular}{|l|c|c|c|}
\hline \multicolumn{1}{|c|}{ S. No. } & At $^{\mathbf{4}} \mathbf{}^{\circ} \mathbf{C}$ & At $^{\mathbf{5}} \mathbf{}^{\circ} \mathbf{C}$ & At $^{\mathbf{6}} \mathbf{}^{\circ} \mathbf{C}$ \\
\hline 1 & 2570 & 2683 & 2574 \\
\hline 2 & 2577 & 2692 & 2573 \\
\hline 3 & 2572 & 2727 & 2578 \\
\hline Mean & 2573 & 2701 & 2575 \\
\hline \% RSD & 0.14 & 0.85 & 0.10 \\
\hline
\end{tabular}

Table 6: Ethanol content at multiple oven temperatures.

RT, area and content were respectively $0.02 \%, 0.82 \%$ and $0.85 \%$ using DB-WAX column, and were $0.01 \%, 0.67 \%$ and $0.67 \%$ using DB-624 column (Table 7). All these values were meeting the acceptance criteria of 1\%, $2 \%$ and $5 \%$ for RT, area and ethanol content using different columns. This data demonstrates that, if GC-column replaced to DB-624 from the standard column DB-WAX, it impacts only on peak RT and area, no impact was observed on ethanol content estimation (Table 7). These experimental data of precision indicating that validated test method is repeatable, rugged and robust. Furthermore, the method was also evaluated for linearity and sensitivity analysis.

\begin{tabular}{|l|c|c|}
\hline S. No. & DB-WAX & DB-624 \\
\hline 1 & 2683 & 2685 \\
\hline 2 & 2692 & 2721 \\
\hline 3 & 2727 & 2699 \\
\hline Mean & 2701 & 2702 \\
\hline \% RSD & 0.85 & 0.67 \\
\hline
\end{tabular}

Table 7: Ethanol content at different GC column.

\section{Sensitivity}

Analytical sensitivity, LOD and LOQ are used to describe the smallest concentration of a compound for detection and quantification by an analytical procedure. This experiment was conducted using ethanol standard of various concentration between 0.2 to 6 ppm, where $\mathrm{R}^{2}$ value was observed 0.9889 and slope was 6410.7 (Figure 6). Based on this experimental data, LOD and LOQ were $1.36 \mathrm{ppm}$ and $4.13 \mathrm{ppm}$ respectively which was estimated using slope value of 6410.7. This study proved that, this analytical method is suitable to detect and quantify ethanol concentration more than 1.36 ppm and 4.13 ppm exclusively.

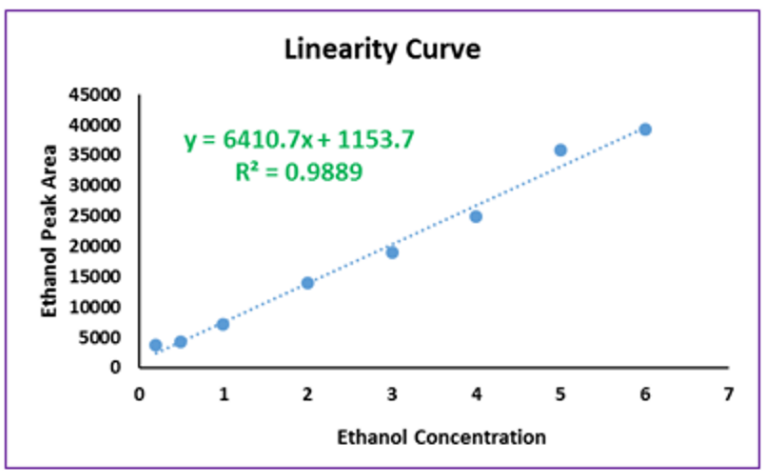

Figure 6: Linearity curve for sensitivity analysis.

\section{Conclusion}

Analytical method validation having a fundamental role in analytical chemistry for releasing accurate and precise data using scientific standards. All analytical methods must be properly validated and documented for quality data and/or regulatory requirements. The specificity study proved that retention time of ethanol is around 3.25 minutes and is comparing with RT of ethanol standard. Accuracy estimation study concluded that mean percentage recovery of this method is $98.10 \%$ and met acceptance criteria of $100 \% \pm 5$. Precision study demonstrated that this method is repeatable, rugged, and robust as reflected data of precision was within the acceptance criteria of percent RSD. As per the data of linearity study, $\mathrm{R}^{2}$ values were 0.9953 and 1 for microalgae sample and standard. This data expressed that, this method is linear till $5000 \mathrm{ppm}$ of ethanol content. Sensitivity study showed that the method is applicable for the analysis of ethanol in biological material, as long as the concentration is more than LOD and LOQ values. This method was validated in accordance with ICH guidelines and all parameters of validation were complied.

Validation data indicated that, this method of ethanol estimation in biological materials can be used as a quality control parameter world-wide. The main features of this method is the short run time, good peak separation, and lower retention time. Sample preparation is not required in this method, algae/water sample can be packed in GC vials and injected into the instrument directly. Sharp and confined ethanol peak was observed using a DB-WAX capillary GC column within a total runtime of 10 minutes. The method is free 
of interference from the ions, salts, metals and biological contaminations. Though the method was only validated for ethanol estimation in micro-algae samples. Same analytical method would be suitable for ethanol estimation in sea water also since algae sample is the mixture of algae, sea water, salts, metals, nutrients, ions and maximum part is sea water which is more than $95 \%$.

\section{Conflict of Interest}

The authors declared that there is no conflict of interest exist in the publication.

\section{Bibliography}

1. Brennan L and Owende P. "Biofuels from micro-algae-a review of technologies for production, processing, and extractions of biofuels and co-products". Renewable and Sustainable Energy Reviews 14 (2010): 557-577.

2. Nigam PS and Singh A. "Production of liquid biofuels from renewable resources". Progress in Energy and Combustion Science 37 (2011): 52-68.

3. Mata TM., et al. "Microalgae for biodiesel production and other applications: a review". Renewable and Sustainable Energy Reviews 14 (2010): 217-232.

4. Demirbas A. "Comparison of transesterification methods for production of biodiesel from vegetable oils and fats". Energy Conversion and Management 49 (2008): 125-130.

5. Song M., et al. "Marine brown algae: a conundrum answer for sustainable biofuels production". Renewable and Sustainable Energy Reviews 50 (2015): 782-792.

6. Kecebas A and Alkan MA. "Educational and consciousness-raising movements for renewable energy in Turkey". Energy Education Science and Technology 1 (2009): 157-170.

7. Fulton LT., et al. "Biofuels for transport: An international perspective". Paris: International Energy Agency (IEA) (2004).

8. Hill J., et al. "Environmental, economic, and energetic costs and benefits of biodiesel and ethanol biofuels". Proceedings of the National Academy of Sciences of the United States of America 103 (2006): 11206-11210.
9. Goldemberg J and Guardabassi P. "The potential for first generation ethanol production from sugarcane". Biofuels Bioproducts and Biorefining 4 (2010): 17-24.

10. Cuellar-Bermudez SP., et al. "Photosynthetic bioenergy utilizing CO2: an approach on flue gases utilization for third generation biofuels". Journal of Cleaner Production 98 (2015): 53-65.

11. Burton T., et al. "A review of the potential of marine algae as a source of biofuel in Ireland". Dublin: Sustainable Energy Ireland- SEI (2009).

12. Yen HW and Brune DE. "Anaerobic co-digestion of algal sludge and waste paper to produce methane". Bioresource Technology 98 (2007): 130-134.

13. Laurens LM., et al. "Algal biomass constituent analysis: method uncertainties and investigation of the underlying measuring chemistries". Analytical Chemistry 84.4 (2012): 1879-188.

14. Vergara-Fernandez A., et al. "Evaluation of marine algae as a source of biogas in a two-stage anaerobic reactor system". Biomass and Bioenergy 32 (2008): 338-344.

15. Nakas JPS., et al. "System development for linked-fermentation production of solvents from algal biomass". Applied and Environmental Microbiology 46 (1983): 1017-1023.

16. Cheng-Wu Z., et al. "An industrial-size flat plate glass reactor for mass production of Nannochloropsis sp. (Eustigmatophyceae)". Aquaculture 195 (2001): 35-49.

17. Besada V., et al. "Heavy metals in edible seaweeds commercialised for human consumption". Journal of Marine Systems 75 (2009): 305-313.

18. Spolaore P., et al. "Commercial applications of microalgae". Journal of Bioscience and Bioengineering 101 (2006): 87-96.

19. Demirbas MF. "Biofuels from algae for sustainable development”. Applied Energy 88.10 (2011): 3473-3480.

20. John RP., et al. "Micro and microalgal biomass: a renewable source for bioethanol". Bioresource Technology 102 (2011): 186-193.

21. Donald TM. "Ethanol fuel use in Brazil". 16th International Symposium on Alcohol Fuels (2006). 
22. Tiscione NB., et al. "Ethanol Analysis by Headspace Gas Chromatography with Simultaneous Flame-Ionization and Mass Spectrometry Detection". Journal of Analytical Toxicology 35 (2011): 501-511.

23. ICH Guideline. "Q2B, Validation of analytical procedures: methodology". in: Proceedings of the International Conference on Harmonization (1996).

24. Helena P., et al. "GC Determination of Acetone, Acetaldehyde, Ethanol, and Methanol in Biological Matrices and Cell Culture". Journal of Chromatographic Science 47.4 (2009): 272-278.

25. Wang ML., et al. "A Rapid Method for Determination of Ethanol in Alcoholic Beverages Using Capillary Gas Chromatography". Journal of Food and Drug Analysis 11.2 (2003): 133-140.

26. Argasiska JG., et al. "Development and validation of gc-fid method for The determination of ethanol residue in marjoram ointment". Acta Poloniae Pharmaceutican Drug Research 66.6 (2009): 611-615.

27. Batista LR and Antoniosi Filho NR. "Ethanol Content Determination in Medicine Syrups Using Headspace and Multidimensional Heart-Cut Gas Chromatography Coupled to Mass Spectrometry". Journal of the Brazilian Chemical Society 31.2 (2020): 394-401.

Volume 4 Issue 6 June 2021

(C) All rights are reserved by Debanjan Sanyal., et al. 